\section{Prenatal diagnosis in India is not limited to sex selection}

To the Editor: We read "Impact of Prenatal Technologies on the Sex Ratio in India: An Overview," by Madan and Breuning, and, as a group of medical geneticists from India, we wish to express our concern regarding the content of this article. Although we do appreciate the good intentions of the authors, we do not agree with some of the particulars mentioned. We also found certain sections of the article to be quite objectionable and irrelevant.

We were disturbed by the implication that prenatal diagnostic techniques are being predominantly used for fetal sex determination in our country. The statement "the Indian medical profession actively promoted it [prenatal diagnosis] for this purpose [prenatal sex selection]" is not only offensive but also untrue, and it portrays the entire medical community of India in a very bad light. Although a very small number of medical professionals might have individually encouraged the use of prenatal diagnostic technology for prenatal sex selection when it was first introduced, the Indian medical community, as a whole, has never endorsed this. The Pre-conception and Prenatal Diagnostic Techniques (Prohibition of Sex Selection) Act of 1994 of the Parliament of India has unequivocally deemed fetal sex determination as a punishable criminal offense, and it is incorrect to generalize and blame the entire medical community for the misdemeanors of some unethical doctors who indulge in illegal practices and violate the principles of this act. Every technology has its flipside and although the misuse of prenatal diagnostic techniques cannot be denied, it has to be remembered that there are hundreds of centers across India that are using these techniques responsibly to provide reliable antenatal diagnosis of malformations and genetic disorders to innumerable affected families. Such negative statements cast a shadow on their good work.

The suggestion of the authors that increasing rates of rape and other crimes against women are directly attributable to the practice of prenatal sex selection does not have any factual basis. These heinous crimes have many complex underlying sociocultural triggers, and it would be too simplistic to consider prenatal sex selection as the principal responsible factor.

The authors have extensively discussed social issues such as child marriage and dowry deaths. We do not wish to downplay these extremely important sociocultural issues, but we would like to point out that these problems are not unique to India and plague many societies across the world. A discussion about them would probably be more relevant in an article about social science rather than genetic science. Moreover, references to statements such as "pay five hundred rupees now rather than five lakhs later" and "raising a girl is like watering a plant in your neighbor's yard" seem very inappropriate for a scientific review article.

There are certain factual errors in the article as well, such as the one about the society in southern India being matriarchal. The matriarchal system is followed in some communities in just one southern state of India-Kerala-and in some groups in northeastern India.

Although there is a lengthy discussion of the status of women in India and the related social issues, this article does not provide any novel suggestions to address these issues. The need for strengthening enforcement of the laws against prenatal sex selection is quite well perceived by doctors, social scientists, lawmakers, and the general public of India, and necessary steps are being taken for the same. The honorable prime minister of India, referring to this issue in his Independence Day address to the country this year, has also mentioned his resolve to implement more stringent measures to check this social menace.

We feel that a rather skewed picture has been presented in the article by Madan and Breuning, ${ }^{1}$ and that the authors could have provided a more balanced and scientifically relevant overview of the prenatal diagnosis scenario in India.

\section{DISCLOSURE}

The authors declare no conflict of interest.

Ashwin B. Dalal, $M D, D M^{1}$, Prajnya Ranganath, $M D, D M^{2}$, Shubha R. Phadke, $M D, D M^{3}$, Madhulika Kabra, $M D^{4}$, Sumita Danda, $M D, D M^{5}$, Ratna Dua Puri, $M D, D M^{6}$, Sankar V.H., $M D, D M^{7}$, Neerja Gupta, $M D, D M^{4}$, S.J. Patil, $M D, D M^{8}$, Kausik Mandal, $M D, D M^{3}$, Parag Tamhankar, $M D, D M^{9}$, Shagun Aggarwal, $M D, D M^{2}$ and Meenal Agarwal, $M D, D M^{3}$

${ }^{1}$ Diagnostics Division, Centre for DNA Fingerprinting and Diagnostics, Hyderabad, India; ${ }^{2}$ Department of Medical Genetics, Nizam's Institute of Medical Sciences, Hyderabad, India; ${ }^{3}$ Department of Medical Genetics, Sanjay Gandhi Postgraduate Institute of Medical Sciences, Lucknow, India; ${ }^{4}$ Division of Genetics, Department of Pediatrics, All India Institute of Medical Sciences, New Delhi, India; ${ }^{5}$ Department of Clinical Genetics, Christian Medical College and Hospital, Vellore, India; ${ }^{6}$ Centre of Medical Genetics, Sir Ganga Ram Hospital, New Delhi, India; ${ }^{7}$ Department of Pediatrics, SAT Hospital, Government Medical College, Trivandrum, Kerala, India; ${ }^{8}$ Narayana Hrudayalaya Hospital, Bengaluru, India; ${ }^{9}$ ICMR Genetic Research Centre, Mumbai, India. Correspondence: Ashwin B. Dalal (ashwindalal@gmail.com)

\section{REFERENCE}

1. Madan $\mathrm{K}$, Breuning $\mathrm{MH}$. Impact of prenatal technologies on the sex ratio in India: an overview. Genet Med 2014;16:425-432.

doi:10.1038/gim.2014.149 